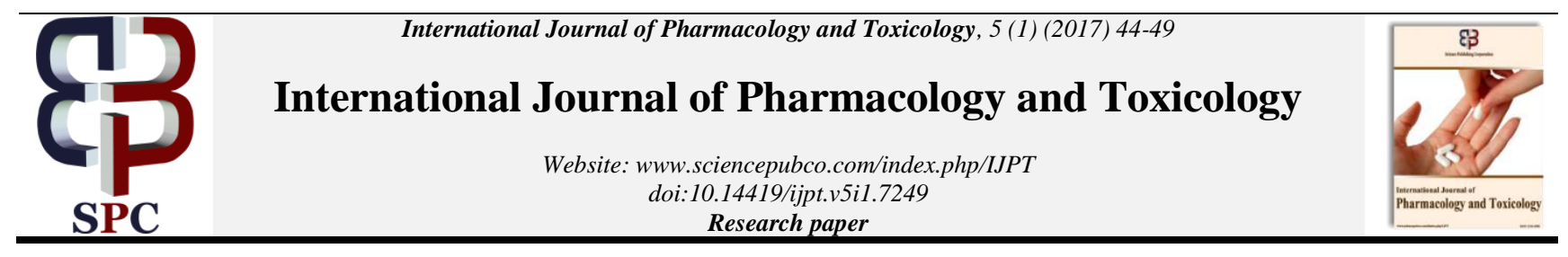

\title{
Protective effect of Matricaria Chamomilla extract on hepatic-renal toxicity of ceftriaxone in rats
}

\author{
Mona Farouk ${ }^{1}$, Seham .Y.Abo-Kora ${ }^{2 *}$, Abdel-Fatah Ali ${ }^{3}$ \\ ${ }^{1}$ Department of Pathology. Faculty of Veterinary Medicine, Benha University, 13736 Moshtohor, Toukh, Qalioubeya,Egypt \\ ${ }^{2}$ Department of Pharmacology. Faculty of Veterinary Medicine, Benha University, 13736 Moshtohor, Toukh, Qalioubeya,Egypt \\ Department of Clinical Pathology, Faculty of Veterinary Medicine, Benha University, 13736 Moshtohor, Toukh, Qalioubeya,Egypt \\ *Corresponding author E-mail:seham_2005asrk@yahoo.com,Edu.email.seham.yousif@fvtm.bu.edu.eg
}

\begin{abstract}
The effect of Matricaria chamomilla (M.chamomilla) against hepatic-renal toxicity of Ceftriaxone was investigated in this study. Twenty eight rats were divided into four groups. The $1^{\text {st }}$ group was injected with saline as control, the $2^{\text {nd }}$ and $3^{\text {rd }}$ groups were injected with M.chamomilla extraction ( $50 \mathrm{mg} / \mathrm{kg} . \mathrm{b} . w \mathrm{t})$ andwith ceftriaxone $\left(180 \mathrm{mg} / \mathrm{kg} . \mathrm{b} . \mathrm{wt}\right.$.) for two and one week respectively while the $4^{\text {th }}$ group was injected with M.chamomilla extraction plus ceftriaxone. at dose $50 \mathrm{mg} / \mathrm{kg}$ and $180 \mathrm{mg} / \mathrm{kg} . \mathrm{b} . \mathrm{wt}$ respectively ,daily for the one week and with M.chamomilla extraction only at dose $50 \mathrm{mg} / \mathrm{kg} . \mathrm{b} . \mathrm{wt}$ for another week. At the end of the $1^{\text {st }}$ week, the $3^{\text {rd }}$ group had significantly higher ALP,ALT,AST, urea and creatinine levels with significantly lower albumin and A/G ratio levels than that of the $1^{\text {stand }} 2^{\text {nd }}$ groups , while the $4^{\text {th }}$ group did not differ from $1^{\text {st }}$ and $2^{\text {nd }}$ groups in terms of these parameters. Histopathological studies revealed that, the $3^{\text {rd }}$ group had some pathological changes in the liver and kidney. From this study we can conclude that, M. chamomilla extraction can reduce hepatic-renal toxicity of ceftriaxone in rats.
\end{abstract}

Keywords: Ceftriaxone; Matricaria Chamomilla; Biochemical Changes; Histopathological.

\section{Introduction}

Chamomile is one of the most common herbs which used for medicinal purposes (Janmejai et al. 2010). There are numerous types of Chamomile, Roman Chamomile and German Chamomile is the most two popular. German Chamomile called Matricaria chamomilla which considered the more potent and received more scientific evaluation (Ragaa et al. 2011). Some chamomile biological effects were confirmed in experimental models and clinical studies (Vandross et al. 2003, Fabian et al. 2011). The dried flowers of chamomile contain many terpenoids and flavonoids that contribute to its medicinal properties (Janmejai et al. 2010). There are different preparations of chamomile that have developed; the most popular one is in the form of herbal tea. Biological effects of chamomile have been confirmed in different experimental models and clinical studies (Vandross et al. 2003)

Ceftriaxone is a bactericidal cephalosporin which is a third generation, resistant to various types of bacterial $\beta$-lactamases; it has effect against Gram-negative and Gram-positive bacteria including Enterobavteriaceae, Haemophilus influenza, Streptococcospnemoniae (Matsuzaki et al. 2005). Ceftriaxone inhibit enzymes that are called transpeptidase enzymes which are responsible for the final step in bacterial cell wall synthesis which has significant stability against beta-hydrolysis (Neu. 1985).

Ceftriaxone is wide distribution in tissues and has rapid absorption as well as body fluids; it is extremely useful in a variety of infectious diseases including meningitis, septicemia, urinary tract, respiratory tract and joints infections (Gohil et al. 2009). Ceftriaxone is widely used in human medicine because of it has prolonged terminal half-life (5.4-8.2h) which allows its prescription on a single administration per day (Bourget et al. 1993). Ceftriaxone undergoes hydrolysis to form active metabolite ceftizoxime in goat (Sar et al. 2006). Ceftizoxime undergoes biotransformation in liver to inactive form metabolite resulting in decrease concentration in blood (Sar et al. 2006, Bakul et al. 2009). The drug is primarily eliminated via the kidneys (33-67\%) with remainder eliminated via the biliary system and bind with calcium ions producing biliary pseudolithiasis(Avci et al. 2016). The liver eliminates a considerable proportion of ceftriaxone in the form of a soluble salt (Avci et al. 2016), ceftriaxone is an anion when its concentration become high these anions bind with calcium ions to form insoluble complexes that precipitate out the biliary system (Shiffman et al. 1990, Park et al. 1991)

Combination of herbs with chemotherapy may be used to decrease adverse effects, elevate the immune function and improve the quality of life in the patients (Ragaa et al. 2011).

Hypothesis of this study is Matricaria Chamomilla extract has protective effect on hepato-renal toxicity which induced during ceftriaxone injection in male albino rats by monitoring the biochemical changes in serum and histopathological findings in liver and kidney.

\section{Material and methods}

\subsection{Drug}

\subsubsection{Ceftriaxone}

Ceftriaxone is a white to yellowish -orange crystal line powder which is soluble in water, produced by Pharco B International for Novartis Pharma.S.A.E. Cairo, Egypt. The drug is supplied for 
intramuscular or intravenous administration in strengths equivalent to $250 \mathrm{mg}, 500 \mathrm{mg}$ and 1 gram of ceftriaxone sodium.

\subsubsection{Preparation of crude extract of Matricaria chamomilla}

M.chamomilla is selected with a fair degree of quality assurance from the farm of Sekem Company (Belbeis Desert Road) which identified by Medicinal and Aromatic Plants Research Department, National Research Centre. Flowering heads were subjected for shade drying then they were powdered. Fifty grams of powdered flowering heads were extracted with $500 \mathrm{ml}$ of $70 \%$ ethyl alcohol for two days. The mixture was sonicated for one hour then the mixture was filtrated. The previous steps were repeated twice on the flowering heads residues. The whole filtrates were concentrated with rotary evaporator on $50^{\circ} \mathrm{C}$ under vacuum until the solution (alcohol + water) was completely removed (Sukhdev et al. 2008). Concentrated extract was weighed and dissolved in known quantity of saline to prepare a stock solution of $50 \mathrm{mg} \mathrm{ml}^{-1}$ concentration and then stored at $4^{\circ} \mathrm{C}$.

\subsection{Experimental design}

Twenty eight adult male albino rats (150-200 gram) obtained from the Animal House, Faculty of Veterinary Medicine, Benha University, Egypt. Rats were housed in clean cages and fed with standard pellet diet and tap water ad libitum, each rat was kept in single metabolic cages under a $12 \mathrm{hr}$ light/dark cycle. Rats acclimatized to the environment for one week before to experimental use.

Rats were divided in four groups, each of seven rats. The $1^{\text {st }}$ group considered as control group was injected with saline intra muscular (IM) once daily for two weeks, the $2^{\text {nd }}$ group was injected with M.chamomilla extraction intra peritoneal (IP) at dose $(50 \mathrm{mg} / \mathrm{kg}$ ) once daily for two weeks, the $3^{\text {rd }}$ group was injected intramuscularly with ceftriaxone at dose $180 \mathrm{mg} / \mathrm{kg}$.b.wt. once daily for one week and the $4^{\text {th }}$ group was injected with ceftriaxone at dose 180 $\mathrm{mg} / \mathrm{kg}$. b.wt. intramuscularly for one week only plus M.chamomilla extraction intra peritoneal (IP) at dose $(50 \mathrm{mg} / \mathrm{kg}$ ) daily for two weeks. Blood samples were obtained from the retroorbital venous plexus. The samples were collected into plain centrifuge tube to separate serum for biochemical analysis. Duration of sample collection from each group was after one and two weeks from the beginning of experiment for biochemical parameters.

\subsection{Biochemical evaluation}

Serum alanine aminotransferase (ALT), aspartate aminotransferase (AST) were measured according to the method of (Reitman et al., 1957), serum alkaline phosphatase (ALP) was measured according to the method of (Glick et al., 1986), Total protein according to (Weichselbaum, 1946), albumin was measured according to the method of (Maier et al., 2007), urea and creatinine were determined in serum using kits from Diamond Diagnostic. Egypt Company, all measured by spectrophotometer

\subsection{Histopathology}

At the end of the $2^{\text {nd }}$ week, all animals sacrificed for tissue sampling. Liver and kidney specimens were fixed in $10 \%$ buffered neutral formalin for histopathological examination. Importantly, tissue samples were also collected after one week from ceftraxione group

\subsection{Statistical analysis}

Data was statistically analyzed by ANOVA with post hock Duncan multiple comparison test using statistical software program (SPSS for Windows version 20, USA). Differences were considered significant at $\mathrm{p}<0.05$.

\section{Results}

\subsection{Biochemical results}

Concerning to the changes in liver enzymes, ALT, AST and ALP after one week, this study confirmed that there was significant increase $(\mathrm{p}<0.05)$ in ALT, AST and ALP levels in ceftriaxone group when compared with control group. Meanwhile there were no significant changes in Matricaria chamomilla group in comparison with control group. Ceftriaxone plus Matricaria chamomilla group showed significant decrease $(\mathrm{p}<0.05)$ in ALT, AST and ALP levels when compared with ceftriaxone group as shown in Table 1.

After two weeks, there were no significant changes in ALT, AST and ALP levels in M. chamomilla group, ceftriaxone group and ceftriaxone plus M. chamomilla group when compared with control group. Similarly, the levels of ALT, AST and ALP enzymes in ceftriaxone plus $M$. chamomilla group showed no significant changes in comparison with ceftriaxone group.

Regarding to the changes in total protein, albumin and globulins levels, there were no significant changes in different groups after one week. On the other hand, after two weeks, there were no significant changes in total protein, albumin and globulins levels in M. chamomilla group and ceftriaxone plus $M$. chamomilla group when compared with control group. Meanwhile, ceftriaxone group showed significant decrease in albumin level associated with no significant changes in total protein and globulin levels in comparison with control group. Importantly, the levels of albumin and A/G ratio were significantly increased in ceftriaxone plus $M$. chamomilla group when compared with ceftriaxone group.

The levels of urea and creatinine after one week showed no significant changes in M. chamomilla group and Ceftriaxone plus $\mathrm{M}$. chamomilla group when compared with control group. Meanwhile, urea and creatinine levels were significantly increased in ceftriaxone group in comparison with control group. On the other hand, ceftriaxone plus $M$. chamomilla group showed significant decrease in urea level associated with no significant changes in creatinine level when compared with ceftriaxone group.

Determination of urea and creatinine levels revealed no significant changes between different groups after two weeks.

\subsection{Histopatholog results}

Liver consisted of hepatic cords around central vein (Fig.1) in control group. Liver showed hydropic degeneration, periductal fibrosis and periductal cell infiltration was noticed around the portal ducts (Fig.2) with mild portal fibrosis and congestion in the portal blood vessels (Fig.3) in Ceftriaxone group after one week, while in Ceftriaxone group after two week, the hepatic tissue showed proliferation in the von kupher cells (Fig.4). In M. chamomilla group, liver consisted of hepatic cords around central vein. No pathological changes in the architecture of the hepatic tissue (Fig.5) while in Ceftriaxone plus M. chamomilla group, the hepatic tissues showed patches of hydropic degeneration and congestion in the portal veins (Fig.6).

Kidney consisted of renal corpuscles (Bowman's capsule) and renal tubules (PCT, DCT, Collecting ducts and connecting pieces (Fig.7) in Control group. The renal tubules were occupied by eosinophilic hyaline casts that obscured the underlying structure (Fig.8) with congestion and edema was noticed in the renal blood vessels (Fig.9) and cloudy swelling in the renal tubules in Ceftriaxone group after one week while, in Ceftriaxone group after two week there is hyaline degeneration was located in the cuboidal cells of the renal tubules (Fig.10). The kidney had the same histological structure as that of the control group with no pathological changes were noticed in the architecture of the renal tissues (Fig.11) in M. chamomilla group, while. Ceftriaxone plus M. chamomilla group the renal blood vessels showed congestion and cloudy swelling in the renal tubule (Fig.12). 
Table1: Serum Biochemical Parameters (Mean \pm SE) in Control, Matricaria Chamomilla, Ceftriaxone and Combined Group after One Week

\begin{tabular}{lllll}
\hline & Control & M. chamomilla & Ceftriaxone & Ceftriaxone+ M.chamomilla \\
\hline ALT (U/I) & $65.34 \pm 4.81^{\mathrm{b}}$ & $68.91 \pm 2.75^{\mathrm{b}}$ & $93.57 \pm 5.99^{\mathrm{a}}$ & $71.93 \pm 4.12^{\mathrm{b}}$ \\
AST (U/I) & $150.28 \pm 4.34^{\mathrm{b}}$ & $178.42 \pm 10.47^{\mathrm{b}}$ & $226.14 \pm 12.91^{\mathrm{a}}$ & $172.14 \pm 9.31^{\mathrm{b}}$ \\
ALP (U/I) & $205.0 \pm 2.88^{\mathrm{c}}$ & $219.42 \pm 8.37^{\mathrm{c}}$ & $355.57 \pm 13.97^{\mathrm{a}}$ & $257.28 \pm 12.13^{\mathrm{b}}$ \\
Total Protein(g/dl) & $7.16 \pm 0.21^{\mathrm{a}, \mathrm{b}}$ & $6.59 \pm 0.37^{\mathrm{b}}$ & $7.12 \pm 0.39^{\mathrm{a}, \mathrm{b}}$ & $7.68 \pm 0.25^{\mathrm{a}}$ \\
Albumin (U/I) & $3.61 \pm 0.20^{\mathrm{a}}$ & $3.21 \pm 0.17^{\mathrm{a}}$ & $3.59 \pm 0.22^{\mathrm{a}}$ & $3.34 \pm 0.18^{\mathrm{a}}$ \\
Globulin (U/I) & $3.55 \pm 0.35^{\mathrm{a}}$ & $3.38 \pm 0.40^{\mathrm{a}}$ & $3.52 \pm 0.39^{\mathrm{a}}$ & $4.34 \pm 0.39^{\mathrm{a}}$ \\
A/G Ratio & $1.11 \pm 0.18^{\mathrm{a}}$ & $1.02 \pm 0.11^{\mathrm{a}}$ & $1.10 \pm 0.14^{\mathrm{a}}$ & $0.83 \pm 0.11^{\mathrm{a}}$ \\
Urea (mg/l) & $16.68 \pm 0.37^{\mathrm{b}}$ & $16.82 \pm 1.03^{\mathrm{b}}$ & $20.80 \pm 0.71^{\mathrm{a}}$ & $17.24 \pm 1.46^{\mathrm{b}}$ \\
Creatinine (mg/l) & $0.72 \pm 0.056^{\mathrm{b}}$ & $0.75 \pm 0.04^{\mathrm{b}}$ & $1.00 \pm 0.057^{\mathrm{a}}$ & $0.84 \pm 0.05^{\mathrm{a}, \mathrm{b}}$ \\
\hline
\end{tabular}

Means in the same row with different superscript letters are significantly different at $\mathrm{P}<0.05$.

Table 2: Serum Biochemical Parameters (Mean \pm SE) in Control, Matricaria Chamomilla, Ceftriaxone and Combined Group after Two Weeks

\begin{tabular}{lllll}
\hline & Control & M. chamomilla & Ceftriaxone & Ceftriaxone+ M.chamomilla \\
\hline ALT (U/I) & $75.71 \pm 3.80^{\mathrm{a}}$ & $70.71 \pm 8.04^{\mathrm{a}}$ & $76.14 \pm 3.64^{\mathrm{a}}$ & $72.00 \pm 2.63^{\mathrm{a}}$ \\
AST (U/I) & $205.28 \pm 33.13^{\mathrm{a}}$ & $235.60 \pm 14.47^{\mathrm{a}}$ & $238.0 \pm 18.27^{\mathrm{a}}$ & $227.50 \pm 13.01^{\mathrm{a}}$ \\
ALP (U/I) & $243.28 \pm 11.98^{\mathrm{a}}$ & $265.42 \pm 6.12^{\mathrm{a}}$ & $274.28 \pm 21.36^{\mathrm{a}}$ & $276.42 \pm 13.31^{\mathrm{a}}$ \\
TotalProtein (g/dl) & $6.44 \pm 0.18^{\mathrm{a}}$ & $6.20 \pm 0.14^{\mathrm{a}}$ & $6.01 \pm 0.16^{\mathrm{a}}$ & $6.15 \pm 0.30^{\mathrm{a}}$ \\
Albumin (U/I) & $3.24 \pm 0.18^{\mathrm{a}}$ & $3.24 \pm 0.18^{\mathrm{a}}$ & $2.37 \pm 0.23^{\mathrm{b}}$ & $3.29 \pm 0.14^{\mathrm{a}}$ \\
Globulin (U/I) & $3.19 \pm 0.17^{\mathrm{a}}$ & $2.96 \pm 0.14^{\mathrm{a}}$ & $3.64 \pm 0.26^{\mathrm{a}}$ & $2.86 \pm 0.35^{\mathrm{a}}$ \\
A/G Ratio & $1.03 \pm 0.09^{\mathrm{a}, \mathrm{b}}$ & $1.12 \pm 0.10^{\mathrm{a}, \mathrm{b}}$ & $0.70 \pm 0.13^{\mathrm{b}}$ & $1.33 \pm 0.26^{\mathrm{a}}$ \\
Urea (mg/l) & $24.69 \pm 2.43^{\mathrm{a}}$ & $27.72 \pm 2.42^{\mathrm{a}}$ & $32.71 \pm 2.79^{\mathrm{a}}$ & $26.07 \pm 1.91^{\mathrm{a}}$ \\
Creatinine (mg/l) & $0.92 \pm 0.01^{\mathrm{a}}$ & $0.85 \pm 0.03^{\mathrm{a}}$ & $0.91 \pm 0.01^{\mathrm{a}}$ & $0.83 \pm 0.04^{\mathrm{a}}$ \\
\hline
\end{tabular}

Means in the same row with different superscript letters are significantly different at $\mathrm{P}<0.05$

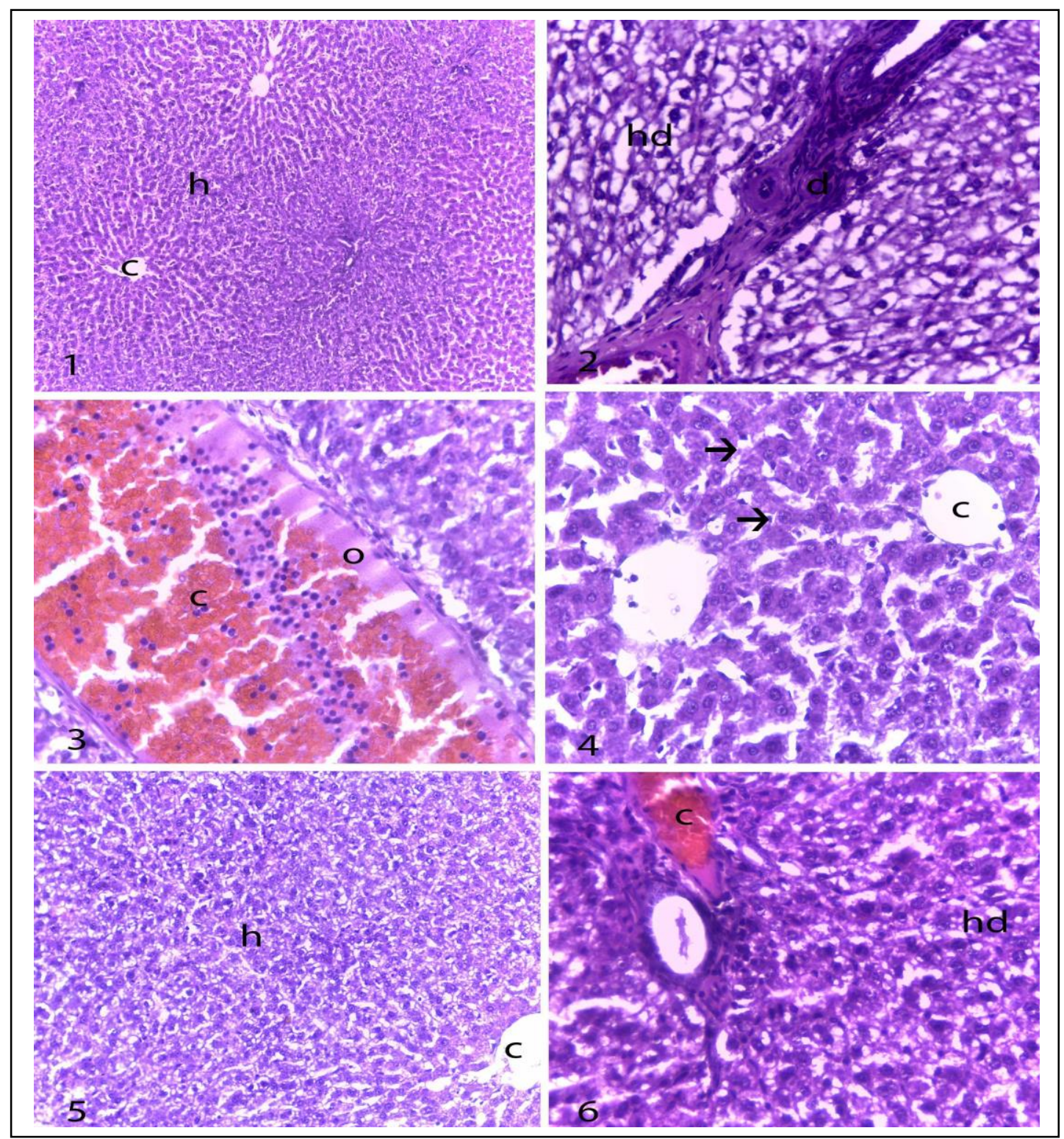

Fig. 1:Liver of the Control Group Showed Central Vein (C) and Hepatic Cord (H) H\&E X10. Fig.2. Liver of Ceftriaxone Group Treated by $180 \mathrm{mg} / \mathrm{Kg}$. B.WtI/M (1 Week) Showed Hydropic Degeneration (Hd) and Periductal Fibrosis (D) H\&E X20. Fig.3. Liver of Ceftriaxone Group (1 Week) 
Showed Congestion (C) and Edema (O) C H\&E X40.Fig.4. Liver of Ceftriaxone Group (2 Weeks) Showed Proliferation of Von Kupher Cells (Arrows).H\&EX20.Fig.5.Liver of Chamomile Group Treated by 50mg/Kg.B.WtI/P Showed Normal Histological Structure, Central Vein (C) And Hepatic Cord $(\mathrm{H}) \mathrm{H} \& \mathrm{E}$ X10. Fig.6.Liver of Ceftriaxone and Chamomile Group Showed Congestion of Blood Vessels (C) and Patches of Hydropic Degeneration (Hd) H\&E X20.

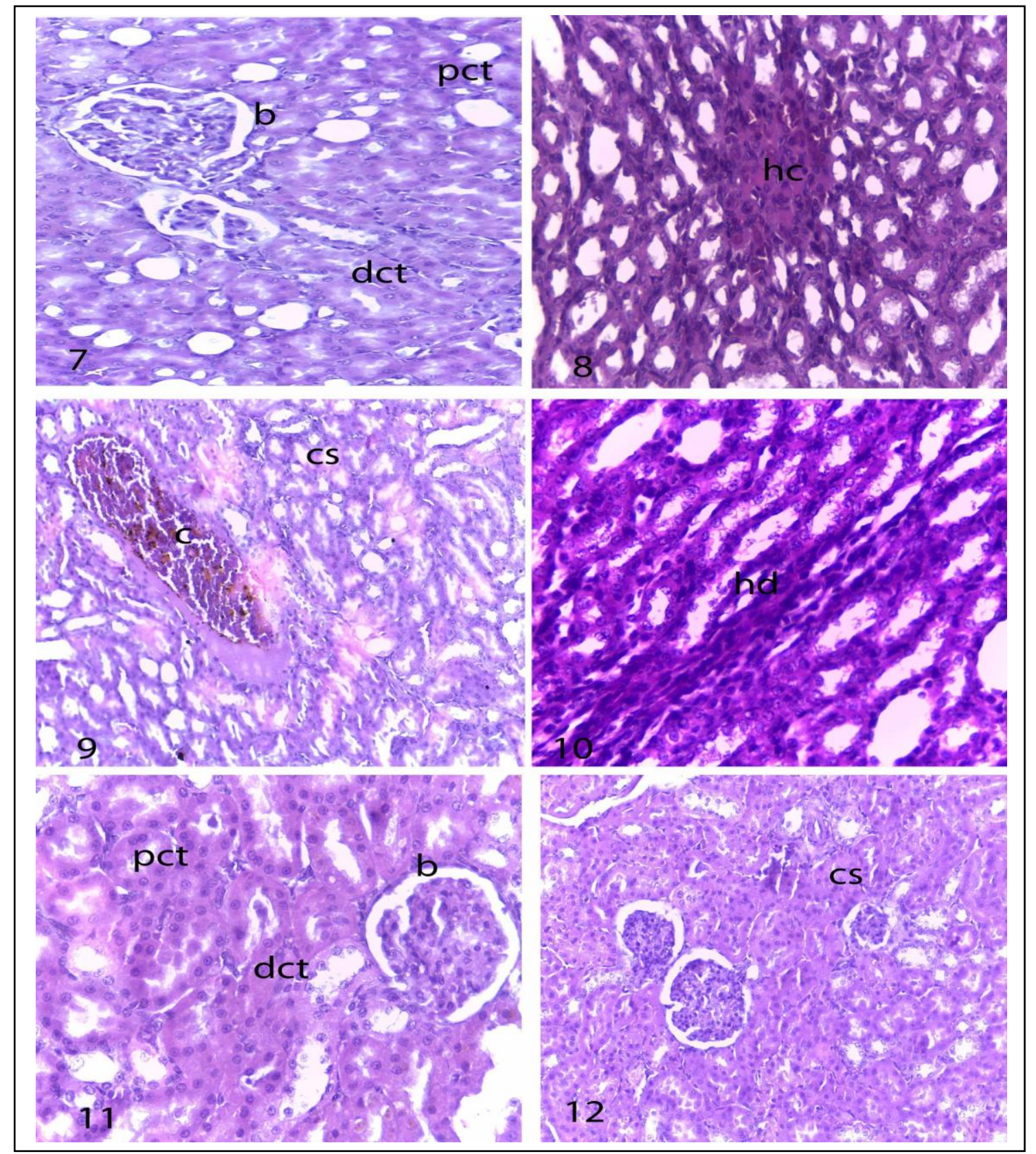

Fig. 7:Kidney of the Control Group Bowman's Capsule (B), Proximal Convoluted Tubules (Pct) and Distal Convoluted Tubules (Dct) H\&E X10. Fig.8. Kidney Of Ceftriaxone Group Treated By 180mg/Kg.B.WtI/M (1 Week) Showed Eosinophilic Hyaline Casts (Hc) H\&E X20. Fig.9. Kidney of Ceftriaxone Group (1 Week) Showed Congestion (C) and Edema and Cloudy Swelling (Cs) H\&E X20. Fig.10. Kidney of Ceftriaxone Group (2 Weeks) Showed Hyaline Degeneration in the Renal Tubules Cells (Hd) H\&E X20. Fig.11.Kidney of Chamomile Group Treated by 50 Mg/Kg.B.WtI/P Showed Bowman's capsule (B), Proximal Convoluted Tubules (Pct) and Distal Convoluted Tubules (Dct) H\&E X10. Fig.12.Kidney of Ceftriaxone and Chamomile Group Showed Cloudy Swelling of the Renal Tubules (Cs) H\&E X20.

\section{Discussion}

Ceftriaxone used as a third generation cephalosporin antibiotic which has a broad spectrum of bactericidal activity (Rajpurohit et al. 2012). The most sensitive biochemical markers in the diagnosis of hepatic dysfunction are AST, ALT, ALP (Nnodim et al. 2010). In this study, there were significant elevation of serum AST and ALT levels in group treated with ceftriaxone for one week. These data indicate severe damage in the liver which is supported by histopathological examination that showed hydropic degeneration and periductal fibrosis .These results consistent with (Malomo,
2000; Ramkumar et al. 2003, Bakul et al. 2009, Elsayed et al. 2011a, Khaled et al. 2014). Also, there is a number of evidence found that ceftriaxone has adverse effects as elevation of the liver enzyme, liver injury, cholestatic abnormalities (Reddy et al. 1995, Elsayed et al. 2011a, Bhamidimarri et al. 2013) . Elevation of AST and ALT may be attributed to increased permeability of hepatocyte due to pathological changes in liver tissues which lead to escape of liver tissue enzymes into circulating blood (Bakul et al. 2009). Histopathological findings in this study were consistent with (Khaled et al. 2014) who recorded that injection of ceftriax- 
one at $180 \mathrm{mg} / \mathrm{kg}$ induced diffuse hydropic degeneration in the hepatocytes of per portal area in rat.

On the hand, the degree of liver damage in group received $\mathrm{M}$. chamomilla during administration of Ceftriaxone showed mild degree of hepatic damage which evidenced by histopathological findings that revealed hydropic degeneration of hepatocytes. Protective effect of M. chamomilla may be attributed to its antimicrobial and moderate antioxidant activities in vitro (Ragaa. 2012), Furthermore, in vivo studies showed that M. chamomilla has potent anti-inflammatory action, cholesterol lowering activities and some antimutagenic as well as antispasmotic effects (McKay et al 2006) Also may be due to bisabololoxide A which is the principle ingredient of German chamomile that has anti-inflammatory action (Ogata et al. 2010, Ragaa et al. 2011, Ragaa. 2012). These findings are in accordance with (Saleem et al. 2010) who reported that the ethanolic extraction of chamomile recutita has reversal effects on liver glutathione, serum bilirubin and serum marker enzymes in hepatotoxicity induced by paracetamol and attributed these results to the hepatoprotective effect of chamomile.

There was significant elevation of serum ALP in this study in group treated by ceftriaxone for one week. This result was similar to that obtained with (Elsayed et al. 2011a) and this elevation related to hepatic cell damage which confirmed by histopathology results (Moss et al. 1974, Gaw et al. 1999). Meanwhile, (Saganuwan. et al. 2006) recorded that AST, ALT and ALP were not affected significantly after intravenous injection of ceftriaxone in turkey. Coadministration of M. chamomilla with ceftriaxone to rats markedly induces reduced serum ALP which manifested histopathologically by improvement in liver tissues lesions. These results may be attributed to the flowers of chamomile contain 1$2 \%$ volatile oils including alpha-bisabololoxids $\mathrm{A}$ and $\mathrm{B}$, alphabisabolol and matricin which converted to chamazulene and other flavonoids which has anti-inflammatory and antiphlogistic properties (Carnat et al. 2004, Janmejai et al. 2010).

There were no significant changes in total protein, albumin and globulins levels in different groups after one week compared with control group. Meanwhile, ceftriaxone group showed significant decrease in albumin level associated with no significant changes in total protein and globulin levels in comparison with control group after two weeks only. These results consistent with (Elsayed et al. 2011a) who reported that serum albumin level decrease after injection of ceftriaxone in rat. These results may be attributed to ceftriaxone displaced bilirubin from albumin so that it used with caution in jaundiced newborns (Gillian et al. 1987), while (Saganuwan. et al., 2006) recorded that albumin and total protein showed no significant changes after intravenous injection of ceftriaxone in turkey. While the levels of albumin and A/G ratio were significantly increased in ceftriaxone plus M. chamomilla group after one week when compared with ceftriaxone group which confirmed with our histopathology results in which improvement in liver tissue lesions which attributed to one of chamomile's anti-inflammatory activities include the inhibition of LPSinduced prostaglandin $\mathrm{E}(2)$ release and attenuation of cyclooxygenase (COX-2)enzyme activity without affecting the constitutive form,COX-1( Srivastava et al. 2009,Janmejai et al. 2010).

Concerning kidney function, there were no significant changes in urea and creatinine levels in $\mathrm{M}$. chamomilla group compared with control group after one week and two weeks. Ceftriaxone group showed significant increase in urea and creatinine levels in comparison with control group after one week of treatment. These results supported by histopathological examination that revealed congestion and edema in the renal blood vessels and cloudy swelling in the renal tubules. These results were consistent with (ElSayed et al. 1997, Kohda et al. 2005, Elsayed et al. 2011b). Meanwhile, ceftriaxone plus $M$. chamomilla group showed no significant changes in urea and creatinine levels when compared with control group after one week.This results consistent with (Ragaa. 2012) ) recorded that administration of M. chamomile extract with cisplatine provided protection for the kidney by decreasing urea and creatinine levels in serum of rat. These finding indicate that $\mathrm{M}$. chamomile extract has protective effect on renal tissues especially when administrated during Ceftriaxone treatment. M. chamomile extract protected the kidney tissues from effect of ceftriaxone which may be attributed to chamomile's antiinflammatory activities (Srivastava et al. 2009, Janmejai et al. 2010). Chamazulene and flavonoid-apigenin constituents of chamomile extract were been shown to exert anti-inflammatory activity in vivo and in vitro (Shipochliev et al. 1981, Verbeek et al. 2004, McKay et al. 2006). In addition to chamomile and its components have antioxidant effects (McKay et al. 2006) .

It is worth mentioned that, the biochemical changes and histopathological finding obtained after two weeks in ceftriaxone group showed improvement in comparison with that obtained after one week in the same group. These results came in agreement with (Bakul et al. 2009) who reported that the residual concentration of ceftriaxone and its metabolite ceftizoxime in blood and various tissues showed a decreased pattern after 7 days onwards..

\section{Conclusion}

Co administration of Matricaria chamomile extraction with ceftriaxone to rats has protective effect against hepatic-renal injury which induced during treatment with ceftriaxone especially with whom suffering from liver and kidney dysfunctions.

\section{Acknowledgments}

The authors grateful to Hend Fouad Esmail, Assistant researcher, Medicinal and Aromatic Plants Research Department, National Research Centre for her advice and help during extraction in this study.

\section{References}

[1] Avci Z, Koktener A, Uras N, Catal F, Karadag A, Tekin O\& et al. (2016) Nephrolithiasis associated with ceftriaxone therapy: a prospective study in 51 children. Arch Dis Child 2004. 89: 10691072.https://doi.org/10.1136/adc.2003.044156.

[2] Bakul KD, Sanjib K, Aditi C, Tapan K, Mandal., Animesh K \& et al. (2009) Long Term Effect Of Ceftriaxone In Black Bengal Goats After Repeated Intramuscular Administration. Pharmacologyonline. 3: 376-393

[3] Bhamidimarri K \& Eugene S (2013) Drug-Induced Cholestasis. Clin Liver Dis. 17: 519531https://doi.org/10.1016/j.cld.2013.07.015.

[4] Bourget P, Fernandez H\&Quinquis V (1993) Pharmacokinetics and Protein binding of ceftriaxone during pregnancy. Antibiotic Agents and Chemotherapy. 37: 54-59https://doi.org/10.1128/AAC.37.1.54.

[5] Carnat A, Carnat A, P., Fraisse D, Ricoux L\&Lamaison J, L (2004) theaeromatic and polyphenolic composition of Roman camomile tea. Fitoterapia. 75: 38.https://doi.org/10.1016/j.fitote.2003.07.007.

[6] El-Sayed M, G., Hassanin. \& Hafez M, R (1997) somepharmacodynamic and biochemical aspects of cefamandole. DtschTierarztlWochenschr. 104(11): 481-487.

[7] Elsayed M, ElkomyA\&Aboubakr M (2011a) Hepatotoxicity evaluation in albino rats exposed to ceftriaxone. Asian J Phar Biol Res. 1: 145-150.

[8] Elsayed MG, ElkomyA\&Aboubakr M (2011b) Evaluation of ceftriaxone nefrotoxicity in albino rats. IJAVMS. 5(2): 153163.https://doi.org/10.5455/ijavms.20110513094308.

[9] Fabian D, Juhás2 S, Bukovská A, Bujňáková D, Grešáková L\& Koppel J (2011) Anti-Inflammatory Effects Of Chamomile Essential Oil In Mice. Slovak J. Anim. Sci. 44(3): 111-116

[10] Gaw A, Cowan R, O’Reilly D, Stewart M\& Shepherd J (1999) Clinical biochemistry an illustrated color text.1st ed .New York:Churchill Livingstone:51-53

[11] Gillian J, Gonard V, Dalmasso C \&Palixc C (1987) Bilirubin displacement by ceftriaxone in neonates: evaluation by determination of'free' bilirubin and erythrocyte bound dose pharmacokinetics of ceftriaxone in bilirubin. Journal of Antimicrobial Chemotherapy. 19 823-829.https://doi.org/10.1093/jac/19.6.823.

[12] Glick M, R., Ryder KW\& Jackson S A (1986) Graphical Comparison of interferances in clinical chemistry instrumentation. Clin. Chem. 32: 470-474 
[13] Gohil PV, Patel UD, Bhavsar SK \&ThakerAM (2009) Pharmacokinetics of ceftriaxone in buffalo calves (Bubalusbubalis) following intravenous and intramuscular administration. Iranian Journal of Veterinary Research, Shiraz University. 10(1): 26

[14] Janmejai K, S., Eswar S \&Saanjay G (2010) Chamomile:A herbal medicine of the past with a bright future. Mol Med Report. 1(3(6)): 896-901

[15] Khaled AA, Sally AE-A, Wafaa IE-I\&Ezz-El-Din SE-D (2014) Protective effects of ursodeoxycholic acid on ceftriaxone-induced hepatic injury in rats. Bulletin of Faculty of Pharmacy, Cairo University.52: 45-50.https://doi.org/10.1016/j.bfopcu.2014.02.002.

[16] Kohda Y, Matsunaga Y\&Yonogi K (2005) Protective effect of serum thymic factor, FTS, on cephaloridine-induced nephrotoxicity in rats. Biol Pharm Bull. 28(11): 2091https://doi.org/10.1248/bpb.28.2087.

[17] Maier S, M., Gross J, K., Hamlin K, L., Maier J, L., Workman J, L., Kim H\& et al. (2007) Proteinuria of nonautoimmune origin in wild -type FVB/NJ mice. Comp.Med. 57: 255-266

[18] Malomo S (2000). Toxicological implications of ceftriaxone administration in rats. Nig J BiochemMol Biol. 15: 33-38

[19] Matsuzaki K, Shito K, Watabe E, Hasegawa M, Sato Y\& Kobayashi I (2005) Antibacterial activity of ceftriaxone against various clinical strains isolated in 2004. Jpn,JAntibiot. $58: 283-289$

[20] McKay D, L \& Blumberg J B (2006) A review of the bioactivity and potential health benefits of chamomile tea (Matricaria recutita L.). Phytother Res. 20: 519-530.https://doi.org/10.1002/ptr.1900.

[21] Moss D\& Butterworth P (1974) Enzymology and medicine. London: Pitman Medical

[22] Neu H C (1985) Relation of structural properties of betalactamantibiotics to antibacterial activity. Am J Med. 79: 213.https://doi.org/10.1016/0002-9343(85)90254-2.

[23] Nnodim J, Emejulu A, AmaechiA\&NwosuNjoku E (2010) Alterations in biochemical parameters of Wistar rats administered with sulfadoxine and pyrimethamine (Fansidar). Al Ameen J Med Sci. 3: 317-321

[24] Ogata I, Kawanai T, Hashimoto E, Nishimura Y, Oyama Y\&Seo H (2010) Bisabololoxide A, one of the main constituents in German chamomile extract, induces apoptosis in rat thymocytes. Arch Toxicol. 84: 45-52.https://doi.org/10.1007/s00204-009-0472-5.

[25] Park H, Z., Lee S P \&Schy A L (1991). Ceftriaxone-associated gallbladder sludge.Identification of calcium-ceftriaxone salt as a major component of gallbladder precipitate. Gastroenterology. 100: 1665-1670.https://doi.org/10.1016/0016-5085(91)90667-A

[26] Ragaa HMS (2012) Matricaria chamomilla Attenuates Cisplatin Nephrotoxicity. Saudi J Kidney Dis Transpl. 23(4): 765 772https://doi.org/10.4103/1319-2442.98158.

[27] Ragaa HMS, Nahed A A., Sary K A, Zaghloul T M\&Nagwa M A G (2011). Nephroprotective Effect of Nigella sativa and Matricaria chamomilla in Cisplatin Induced Renal Injury. International Journal of Clinical $\quad$ Medicine. 195.https://doi.org/10.4236/ijcm.2011.23031.

[28] Rajpurohit H, Kumar V B, Sharadamma K \&Radhakrishna P (2012) Comparative study of antimicrobial activity of ceftriaxone in combination with sulbactam and tazobactam using disc diffusion. Method. Int J Pharm. 3: 331-334.Ramkumar D.

[29] LaBrecque D (2003) Drug-induced liver disease and environmental toxins. In: Zakim D, Boyer T, editors. Hepatology: a textbook of liver disease. Philadelphia: Saunders. 755-832

[30] Reddy K \& Schiff E (1995) Hepatotoxicity of antimicrobial, antifungal,andantiparasitic agents. GastroenterolClin North Am. 24:923-36).

[31] Reitman S \& Frankel S (1957) A calorimetric method for the determination of GOT and GPT. American J. of Clin.Pathol. 28: 5663https://doi.org/10.1093/ajcp/28.1.56.

[32] Saganuwan\&Alhaji S (2006) Effects Of Ceftriaxone onHaematologicaland Biochemical Parameters of Turkey. Animal Research International. 3(3): 562-565.

[33] Saleem TSM, Chetty CM, Ramkanth S, Rajan VST\& Kumar KM (2010) Hepatoprotective Herbs - A Review. Int. J. Res. Pharm. Sci. 1(1): $1-5$

[34] Sar T, K., Mandal T K., Das S K, Chakraborty AK \& Bhattacharyya A (2006) Pharmacokinotics of ceftriaxone in healthy and mastitic goats with special reference to its interaction with polyherbal drug (Fibrosin $®)$. International journal of applied residue and veterinary medicine. 4(2): 142-154

[35] Shiffman M L, Keith F B \& Moore E W (1990) Pathogenesis of ceftriaxone-associated biliary sludge. In vitro studies of calciumceftriaxone binding and solubility. Gastroenterology. 99: 17721778.https://doi.org/10.1016/0016-5085(90)90486-K
[36] Shipochliev T, DimitrovA\&Aleksandrova E (1981) Antiinflammatory action of a group of plant extracts. Vet. Med. Nauki. 18: 87-94.

[37] Srivastava J K, Pandey M \&Gupta S (2009) Chamomile, a noval and selective Cox-2 inhibitor with anti-inflammatory activity. Life Sci. 85: 663-669.https://doi.org/10.1016/j.lfs.2009.09.007.

[38] Sukhdev SH, Suman PSK, Gennaro L\&Dev DR (2008) Extraction Technologies for Medicinal and Aromatic Plants. International Centre For Science And High Technology Trieste

[39] Vandross R., Xue Y., Knudson A.\&Pelling JC(2003) The chemopreventive bioflavonoid apigenin modulates signal transduction pathways in keratinocyte and colon carcinoma cell lines, J Nutr, 133 3800S-3804S

[40] Verbeek R, Plomp Ac, Van TolEa\&Van NoortJm (2004) The flavones luteolin and apigenin inhibit in vitro antigen-specific proliferation and interferon-gamma production by murine and human autoimmune $\mathrm{T}$ cells. Biochem. Pharmacol, 15: 621629.https://doi.org/10.1016/j.bcp.2004.05.012.

[41] Weichselbaum TE (1946) an a curate rapid for determination of protein small amount of blood serum and plasma. Am. J. Clin. Pathol. 